Bangladesh J. Bot. 48(4): 1021-1028, 2019 (December)

\title{
MAPPING QUANTITATIVE TRAIT LOCI FOR COLD TOLERANCE IN RICE AT SEEDLING STAGE
}

\author{
Nomita Das, Nazmul Alam, Kamal Hossain and Partha S Biswas*1 \\ Department of Botany, Jahangirnagar University, Savar, Dhaka-1340, Bangladesh \\ Keywords: Quantitative trait loci, Cold tolerance, Seedling stage, Rice
}

\begin{abstract}
Rice plants are sensitive to cold stress at various growth stages starting from germination to maturity. Exploitation of cold tolerance for the development of cold tolerant varieties may help in saving crop loss or cost of production in the cold prone environment. Introgression of quantitative trait loci (QTLs) conferring cold tolerance in the elite variety may be the most effective and sustainable approach to address this issue. A $\mathrm{F}_{2: 3}$ mapping population of a cross between a cold susceptible variety (BR1) and a cold tolerant variety (BR18) was used to map QTLs for cold tolerance at seedling stage. Three significant QTLs on chromosomes 1, 3 and 12 associated with cold tolerance were mapped between the markers intervals of RM220-RM10829, RM546-RM7 and RM27877-RM463, respectively at a threshold LOD of 4.3 through composite interval mapping. Phenotypic contributions of these QTLs were 50.7, 39 and 52.7\%, respectively. Marker information of such a large effect QTL could be used in the breeding program after necessary validation to develop cold tolerant high yielding rice varieties.
\end{abstract}

\section{Introduction}

Cold stress is one of the major abiotic stresses affecting rice crop at seedling stage in the northern parts of Bangladesh. Germination and seedling establishment are very sensitive growth stages of rice to cold stress. Seedling mortality ranging from $10-90 \%$ is observed in some years at early establishement stage of Boro rice crop in the northern districts of Bangladesh when severe cold spell occurs in late December to mid January. This entails increased cost of production for replanting, which is a great problem for the marginal farmers. Farmers sometimes delay planting to avoid seedling mortality caused by low temperature, which eventually lowers the grain yield of Boro rice due to exposure of reproductive phase in high temperature in April. To overcome this problem, use of rice varieties tolerant to cold stress at seedling stage could be a sustainable crop management approach. In the cold prone area in Bangladesh, farmers commonly grow major high yielding varieties like, BRRI dhan 28 and BRRI dhan29 but they lack cold tolerance. Although, there are other few cold tolerant rice varieties (BRRI dhan36 and BRRI dhan55) that were developed through conventional breeding method by BRRI, but their performance is not good enough to address the cold injury problem in Boro rice. Furthermore, the rice varieties which are popularly grown in South and South-east Asian countries and are preferred by the consumers usually lack cold tolerance. However, there are rice germplasm that can tolerate cold stress and can maintain better growth than the intolerant one under low temperature stress conditions. Exploitation and use of cold tolerance from such germplasm in development of high yielding rice varieties could save crop loss or cost of cultivation. Therefore, exploring genetic resources to develop cold tolerant rice variety is essential. Molecular analysis of QTLs underlying cold tolerance is the best approach to develop cold tolerant varieties.

\footnotetext{
*Author for correspondence: <psbiswasbrri@yahoo.com>. ${ }^{1}$ Plant Breeding Division, Bangladesh Rice Research Institute, Gazipur-1701, Bangladesh.
} 
Several reports on quantitative trait loci (QTL) for seedling stage cold tolerance in rice is available in literature (Andaya and Mackill 2003, Lou et al. 2007, Zhi-Juan et al. 2010, Kim et al. 2012, Suh et al. 2012, Yang et al. 2013, Park et al. 2013). Marker information and corresponding donor germplasm of these studies can be used to develop cold tolerant and high yielding rice varieties through marker assisted selection. However, the donor germplasms used in these studies are of japonica origin. The crosses between indica and japonica rice usually produce progenies with higher spikelet sterility due to inter-subspecific reproductive barrier. Furthermore, japonica types are not adaptable to tropical condition and are not preferred by the consumers in South Asian countries like Bangladesh due to their sticky cooked rice. Use of indica donors in the breeding program to develop cold tolerant rice is the best way to avoid such unexpected linkage drag in the high yielding background, although level of cold tolerance in indica rice is poor and occurrence of higher tolerance is extremely rare. BRRI has identified BR18 as a potential donor for cold tolerance at seedling stage (Biswas et al. 2012). Therefore, this study was undertaken to map QTLs from a $\mathrm{F}_{2: 3}$ mapping population of $\mathrm{BR} 1 \times \mathrm{BR} 18$.

\section{Materials and Methods}

A set of $856 \mathrm{~F}_{2: 3}$ mapping population derived from a cross between BR1 and BR18 was used for this study. All the field and laboratory work for this study were conducted at Plant Breeding Division of Bangladesh Rice Research Institute, Gazipur, Bangladesh in collaboration with Department of Botany, Jahangirnagar University, Savar, Dhaka, Bangladesh. BR1 is a cold susceptible high yielding variety at seedling stage. On the other hand, BR18 is cold tolerant rice variety at seedling stage. Although BR18 is a high yielding variety developed by BRRI for Haor regions of the country, its tall stature does not fit to the cold prone northern districts of Bangladesh.

The $\mathrm{F}_{2: 3}$ progenies were evaluated for cold tolerance using cold treatment of constant $13^{\circ} \mathrm{C}$ in a cold-water tank following Khatun et al. (2016). Briefly, seeds were sown in plastic trays filled with gravels and crop residue free granular soil with 3 replicates. Ten seedlings of each entry were raised at ambient temperature at each replication. At three-leaf stage (12 - 14 days after seeding), the plastic trays were placed in cold water tanks preset at $13^{\circ} \mathrm{C}$. The depth of water in the tank was maintained at $5 \mathrm{~cm}$. Temperature of cold water tank was kept at constant $13^{\circ} \mathrm{C}$ for 6 days or until the susceptible check variety dies. An arbitrary leaf discoloration (LD) scores (1 to 9; 1 means all leaves are green and 9 means seedlings are almost dead) was assigned to each entry considering magnitude of discoloration of leaves due to low temperature treatment on the day of LD scoring following standard evaluation system (SES) of IRRI (IRRI 2013).

Parental polymorphism information of around 560 SSR markers distributed over rice genome for BR1 and BR18 was analyzed using method described by Syed et al. (2016). Briefly, DNA was extracted from young and actively growing fresh leaves using miniprep modified CTAB method. Polymerase chain reaction (PCR) was performed in $10 \mu \mathrm{l}$ volume containing $2 \mu \mathrm{l}$ of genomic DNA, $5.3 \mu \mathrm{l}$ of $\mathrm{DDH}_{2} \mathrm{O}, 1 \mu \mathrm{l}$ of $1 \mathrm{X}$ PCR buffer, $1 \mu \mathrm{l}$ of $0.1 \mathrm{mM}$ dNTP mix, $0.5 \mu \mathrm{l}$ of $0.25 \mu \mathrm{M}$ of each primer, $2 \mu \mathrm{l}$ of Taq polymerase of $1 \mathrm{U}$. The temperature cycles were programmed at $94^{\circ} \mathrm{C}$ for $5 \mathrm{~min}$ (initial denaturation), $94^{\circ} \mathrm{C}$ for $30 \mathrm{sec}$ (denaturation), $55^{\circ} \mathrm{C}$ for $30 \mathrm{sec}$ (primer annealing), $72^{\circ} \mathrm{C}$ for $60 \mathrm{sec}$ (extension), $72^{\circ} \mathrm{C}$ for $5 \mathrm{~min}$ (final extension) and $10^{\circ} \mathrm{C}$ forever (storage). The PCR product was separated on $6 \%$ polyacrylamide gel through electrophoresis for 1.5 to $2.5 \mathrm{hrs}$ and was visualized in a gel documentation system. Parental polymorphism was determined based on the comparative deviation in band position.

Selective genotyping technique (Lander and Botstein 1989) was used to select plants for genotyping. A set of $40 \mathrm{~F}_{2}$ plants along with their parents were used in genotyping with 76 
polymorphic SSR markers distributed over 12 chromosomes of rice. Allele scoring was performed based on comparative position of the parental DNA bands. The progeny having band at same level of BR18's band was scored as 'A' and the progeny having band at same level of BR1's band was scored as 'B' while heterozygous alleles were scored as 'H' (Fig.1). .

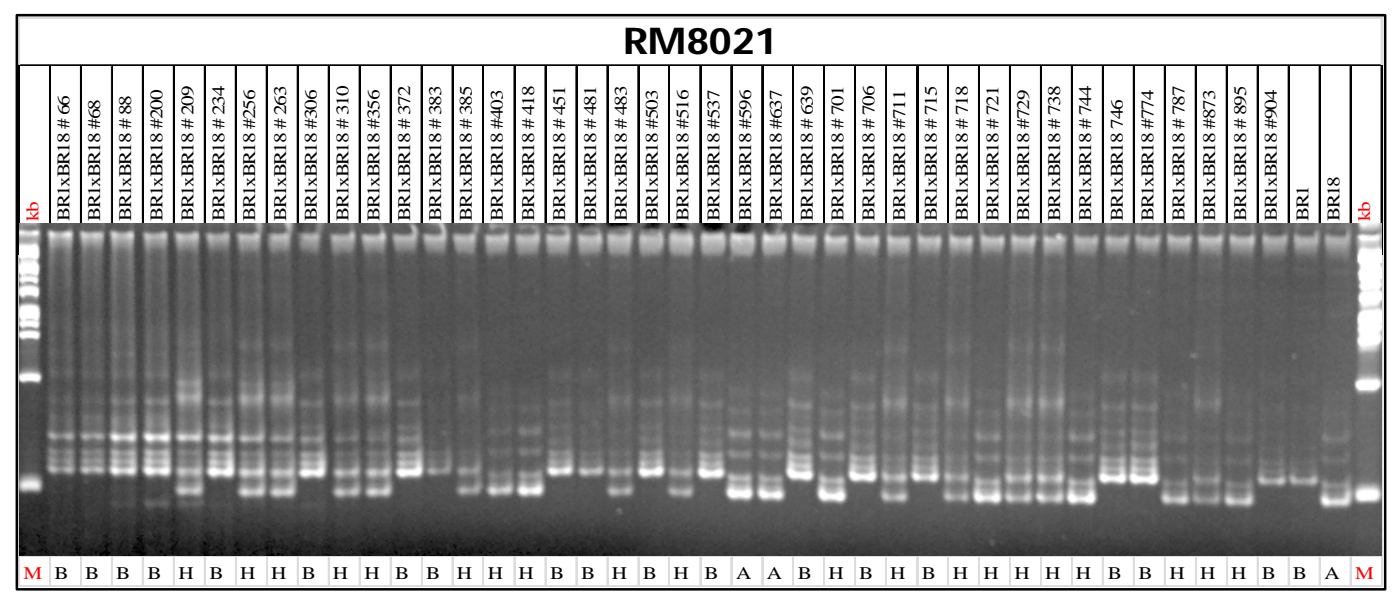

Fig. 1. A partial gel image of genotyping of $40 \mathrm{~F}_{2}$ progenies along with parental lines with RM8021; M represents marker of $1 \mathrm{~Kb}$ DNA ladder; A, B and $\mathrm{H}$ represent homozygous BR18, homozygous BR1 allele, heterozygous allele, respectively.

Construction of linkage map and detection of QTLs for cold tolerance were performed using QGene4.0 (Nelson 1997). Each marker was analysed through single marker analysis (SMA). To be more precise about the location of the identified QTLs, interval mapping (IM) and composite interval mapping (CIM) analysis were performed. Permutation test was performed with 1000 interations to declar threshold LOD (Logarithm of Odds) for significant QTL at 5\% level of probability. The proportion of the total phenotypic variation explained by each QTL was calculated as $R^{2}$ value $\left(R^{2}=\right.$ Ratio of the sum of squares explained by the QTL to the total sum of squares). The QTLs were named based on the nomenclature suggested by McCouch et al. (1997).

\section{Results and Discussion}

Cold tolerance at seedling stage of $856 \mathrm{~F}_{2: 3}$ progenies was evaluated using cold induced leaf discoloration (LD) pattern at low temperature $\left(13^{\circ} \mathrm{C}\right)$. Analysis of variance (ANOVA) showed that the progenies had significantly variable LD values ranging from 1 to 9 with an average of 5.1 (Table 1). The LD values showed a moderate heritability estimate and apparently normal frequency distribution pattern (Fig. 2) having skewness and kurtosis very close to unity. On the other hand, the susceptible parent BR1 showed significantly higher LD value than that of BR18. Continuous variation in frequency distribution in cold induced leaf discoloration and cold induced necrosis was also reported by Andaya and Mackill (2003), in percent seedling survival by Lou et al. (2007) and Zhang et al. (2005), in seedling height and seedling dry weight by Han et al. (2007) and germination rate by Ranawake et al. (2014). Continuous variation in frequency distribution reveals that the trait is quantitatively inherited, which warrants QTL mapping. The skewness and kurtosis values of the frequency distribution that were very close to unity also supported the suitability of the phenotypic data for QTL analysis. 
Table 1. Descriptive statistics of leaf discoloration scores of $856 \mathrm{~F}_{2: 3}$ progenies.

\begin{tabular}{ll}
\hline Descriptive statistics & \multicolumn{1}{c}{ Value } \\
\hline Parents & \\
LD value of BR1 & $8.8^{* *} \pm 0.12$ \\
LD value of BR18 & $2.1 \pm 0.19$ \\
\hline F $2: 3$ progenies $^{*}$ & \\
Average & 5.1 \\
Range & $1-9$ \\
CV & 30.16 \\
\hline P- value & 0.0002 \\
Skew & 0.09 \\
Kurtosis & -0.78 \\
$\mathrm{~h}^{2} \mathrm{~b}$ & 40.4 \\
\hline
\end{tabular}

$\mathrm{LD}$, leaf discoloration, **, significant at $1 \%$ level of probability.

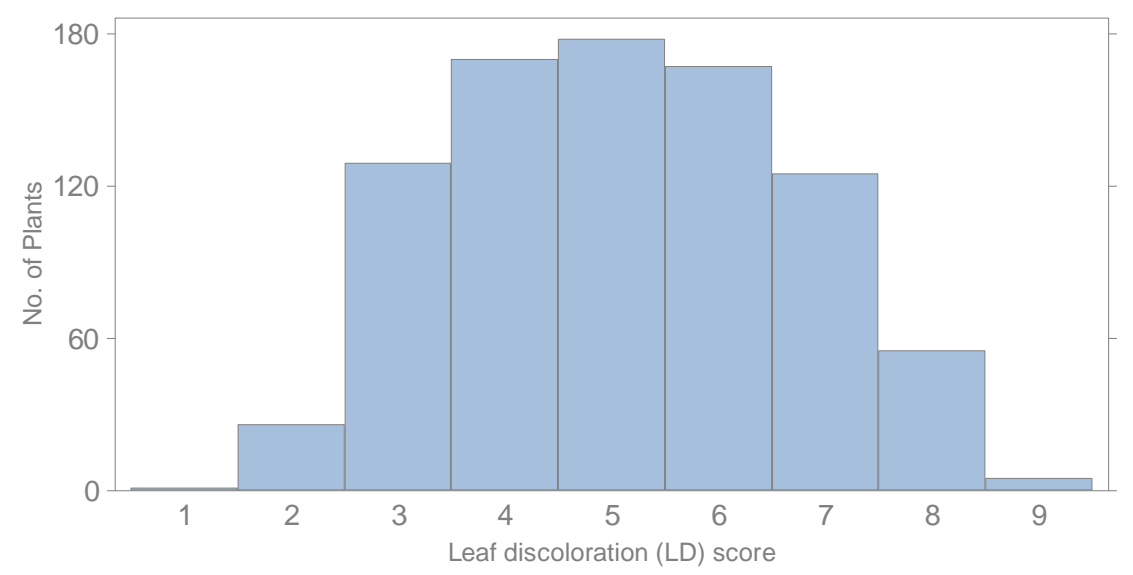

Fig. 2. Frequency distribution of LD scores in $856 \mathrm{~F}_{2: 3}$ families of $\mathrm{BR} 1 \times \mathrm{BR} 18$.

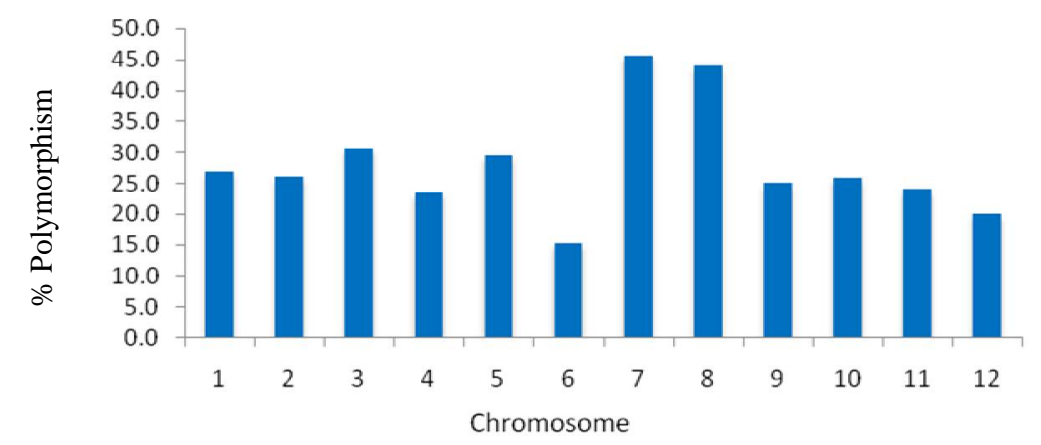

Fig. 3. Chromosome-wise SSR marker polymorphism between BR1 and BR18. 
A parental survey was conducted with 560 microsatellite markers to identify at least one polymorphic marker per $20 \mathrm{cM}$ throughout the genome of the parental lines. Fig. 3 shows the percentage of polymorphic SSRs distributed on rice chromosomes. The polymorphism rate across 12 chromosomes ranged from 15.2 to $45.7 \%$ with an average of $28 \%$. The highest polymorphism rate was observed on chromosome 7 followed by on chromosome 8 (43.9\%) and chromosome 3 (30.6\%). The minimum polymorphism rate was observed on chromosome $6(15.2 \%)$. The extent of polymorphism between the parental lines depends on the genetic distance between them. The closely related cultivars (indica $\times$ indica or japonica $\times$ japonica) usually show lower polymorphism than the genetically diverged cultivars (indica $\times$ japonica). The lower polymorphism rate in present study might be due to their indica origin. Septiningsih et al. (2012) reported 115 polymorphic and reliable SSR markers out of 1,074 (10.5\%). Similar results were obtained when linkage map was constructed using a japonica /japonica mapping population (Bing et al. 2006).
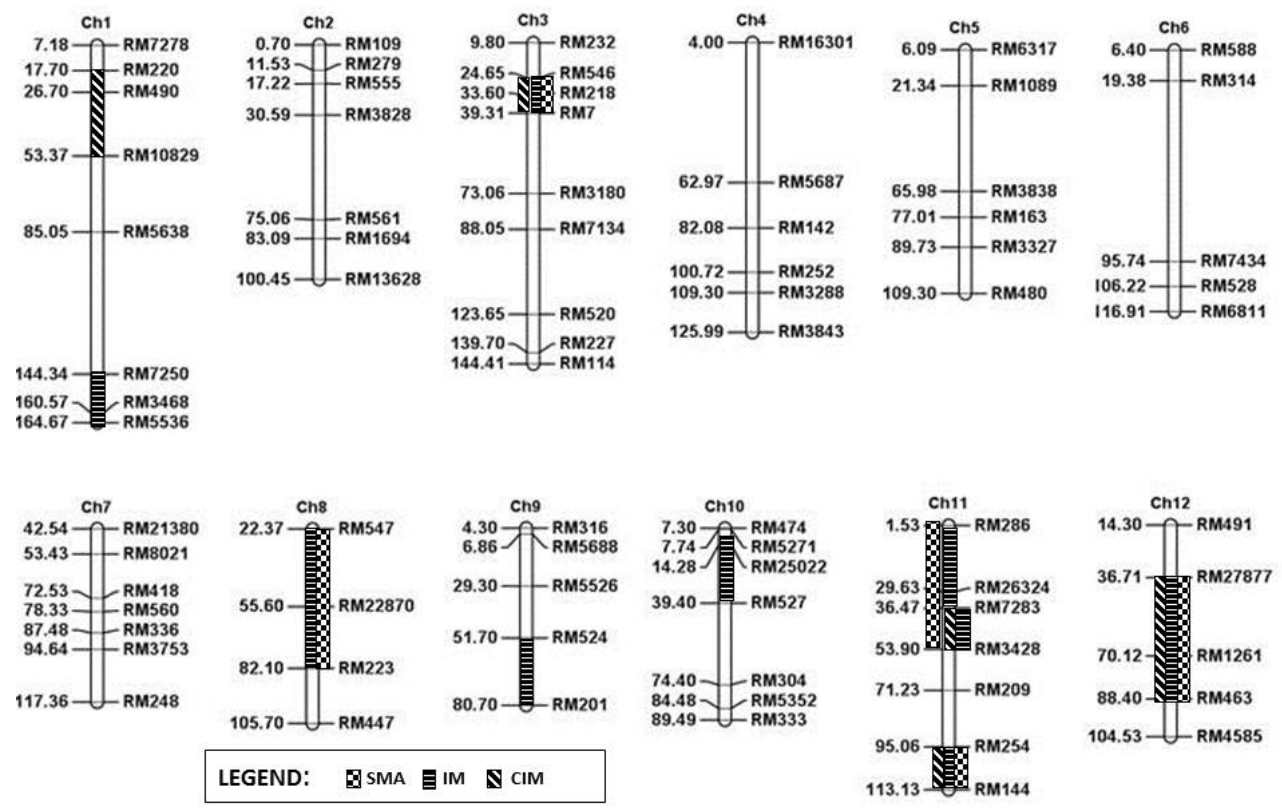

Fig. 4. Linkage map of $40 \mathrm{~F}_{2: 3}$ families from BR1× BR18 with 76 polymorphic SSR markers using QGene 4.0. QTLs detected through SMA, IM and CIM were overlaid on respective chromosomal position.

Linkage map of 12 chromosomes was constructed with 76 polymorphic SSR markers using QGene 4.0 (Nelson 1997) (Fig. 4). The map covered $1346.1 \mathrm{cM}$ of rice genome in length (cM data was obtained by multiplying corresponding physical distance with 3.96) with an average marker interval of $19.5 \mathrm{cM}$. There were still a few gaps larger than $20 \mathrm{cM}$ on all the chromosomes. The progenies from the extreme tails of frquency distribution of LD score were considered for genotyping following selective genotyping technique (Lander and Botstein 1989). This genotyping technique not only helps truncate many $\mathrm{F}_{2}$ population into a judicious sized mapping population with no significant sacrifice of phenotypic variation but also it enriches frequencies of contrasting alleles and thus it is a commonly used genotyping strategy to reduce genotyping cost (Collard et al. 2005). In the present study, out of $856 \mathrm{~F}_{2: 3}$ progenies, 40 plants that account for around $2.3 \%$ progenies from either upper and bottom tails of the frequency distribution were sampled for 
genotyping (Fig. 5). The truncated chunk of the genotypes had contrasting LD values of 2.6 - 4.2 at bottom tail and $7.8-9.0$ at upper tail, which were closer to the parental LD values (Table 1).

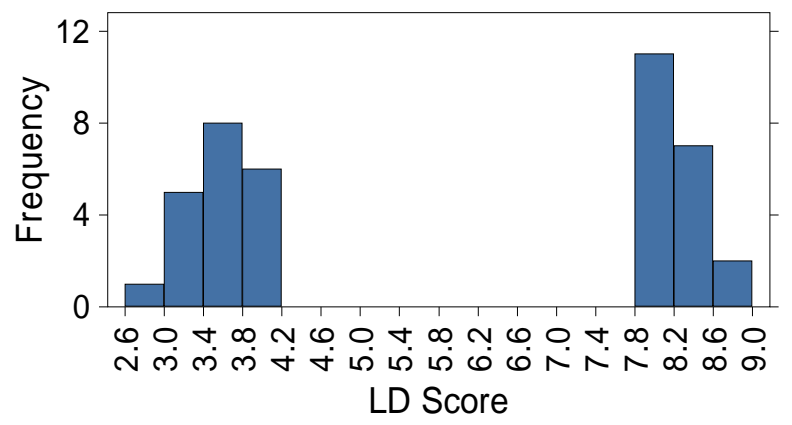

Fig. 5. Frequency distribution of LD score of the selcted progenies from the extreme ends of cold sensitivity.

Genotyping of $40 \mathrm{~F}_{2}$ plants with 76 polymorphic SSR markers covering $1346.1 \mathrm{cM}$ of rice genome reveals 11 putative chromosomal segments responsible for cold tolerance when genotype and phenotype data were subjected to SMA, SIM and CIM analysis (Fig. 4). Out of 11 QTLs, six, eight and five QTLs were identified through single marker analysis, interval mapping and composite interval mapping, respectively. Three QTLs were common among three methods of QTL detection. Maximum four QTLs were mapped on chromosome 11 and single QTL was mapped on each of chromosomes 3, 8, 9 and 12. Two QTLs were detected on chromosome 1. Out of five QTLs that were detected through CIM, three QTLs were found significant at a threshold LOD of 4.3 at $5 \%$ level of significance in permutation test with 1000 iterations (Table 2).

Table 2. Putative QTLs identified for seedling stage cold tolerance from $F_{2: 3}$ mapping population of BR1 $\times$ BR18 through single marker analysis, interval mapping and composite interval mapping.

\begin{tabular}{|c|c|c|c|c|c|c|c|c|c|c|c|c|}
\hline \multirow{2}{*}{$\begin{array}{l}{ }^{\mathrm{a}} \mathrm{QTL} \\
\text { name }\end{array}$} & \multirow[t]{2}{*}{ Chr. } & \multirow{2}{*}{$\begin{array}{l}\text { Peak } \\
\text { marker }\end{array}$} & \multirow{2}{*}{$\begin{array}{l}\text { QTL } \\
\text { bordering } \\
\text { marker }\end{array}$} & \multicolumn{3}{|c|}{ SMA } & \multicolumn{3}{|c|}{ IM } & \multicolumn{3}{|c|}{ CIM } \\
\hline & & & & LOD & $\begin{array}{l}{ }^{{ }^{b} \mathrm{R}^{2}} \\
(\%)\end{array}$ & $\begin{array}{c}\text { Additive } \\
\text { effect }\end{array}$ & LOD & $\begin{array}{l}\mathrm{R}^{2} \\
(\%)\end{array}$ & $\begin{array}{c}\text { Additive } \\
\text { effect }\end{array}$ & ${ }^{\mathrm{c}} \mathrm{LOD}$ & $\begin{array}{l}\mathrm{R}^{2} \\
(\%)\end{array}$ & $\begin{array}{c}\text { Additive } \\
\text { effect }\end{array}$ \\
\hline$q C T S 1.1$ & 1 & RM490 & $\begin{array}{l}\text { RM220 - } \\
\text { RM10829 }\end{array}$ & - & - & - & - & - & - & $6.1 *$ & 50.7 & -1.15 \\
\hline$q C T S 3$ & 3 & RM218 & RM546-RM7 & 7.3 & 57.2 & -1.8 & 5.23 & 45.2 & -0.216 & $4.3 *$ & 39.0 & -0.54 \\
\hline$q C T S 11.2$ & 11 & RM7283 & $\begin{array}{l}\text { RM7283- } \\
\text { RM3428 }\end{array}$ & - & - & - & 3.51 & 33.3 & -1.37 & 3.6 & 34.3 & -0.84 \\
\hline$q C T S 11.4$ & 11 & RM144 & $\begin{array}{l}\text { RM254- } \\
\text { RM144 }\end{array}$ & 4.1 & 38.1 & -0.8 & 3.42 & 31.3 & 1.78 & $2.9^{\mathrm{ns}}$ & 27.4 & -0.8 \\
\hline$q C T S 12$ & 12 & RM1261 & $\begin{array}{l}\text { RM27877- } \\
\text { RM463 }\end{array}$ & 9.6 & 66.9 & 2.2 & 11.41 & 73.1 & 2.55 & $6.5^{*}$ & 52.7 & 1.58 \\
\hline
\end{tabular}

CTS, cold tolerance at seedling stage. ${ }^{\mathrm{I}}$ Individual QTL is designed with $\mathrm{q}$ indicating QTLs with LOD > 2.5, an abbreviation of the trait name and the chromosome number on the chromosome, suggestive QTLs are indicated in italic. ${ }^{\text {b} P o r t i o n ~ o f ~ p h e n o t y p i c ~ v a r i a t i o n ~ e x p l a i n e d ~ b y ~ t h e ~ i n d i v i d u a l ~ Q T L . ~}{ }^{\mathrm{C}}$ Significant loci after 1000 permutation analysis at $\mathrm{p}<0.05$ with threshold LOD (Logarithm of Odds) of 4.3 . *Significant at $5 \%$ level of significance. ${ }^{\mathrm{ns}}$ Null significant showed after significant analysis. 
The significant QTLs were located on chromosomes 1, 3 and 12 with marker intervals of RM220 - RM10829, RM546 - RM7 and RM27877 - RM463, respectively. Several previous studies also reported QTLs on chromosomes 1, 3 and 12. Park et al. (2013), Liu et al. (2013) and Zhi-Juan et al. (2010) reported QTLs for seedling stage cold tolerance on chromosome 1 at 2.6 $4.2 \mathrm{Mb}, 0.5-4.0 \mathrm{Mb}$ and $0.5-4.0 \mathrm{Mb}$, respectively; similarly Zhi-Juan et al. (2010) and Zhang et al. (2014) reported QTLs on chromosome 3 at 9.9-12.4 Mb and $19.8-23.1 \mathrm{Mb}$, respectively; while Han et al. (2007), Zhang et al. (2013), Andaya and Mackill (2003) and Verma et al. (2014) reported QTL (qCTS12) on chromosome 12 at 17.8 - 26.9 Mb, 3.8 - 5.8 Mb, 8.8 - 9.6 Mb and 4.9 - 5.3 Mb, respectively. But the physical positions of QTLs of the present trait were different from those of previously reported QTLs. We mapped qCTS1.1 at 4.4 Mb - 13.3 Mb on chromosome 1, $q C T S 3$ at $6.2 \mathrm{Mb}-9.8 \mathrm{Mb}$ on chromosome 3 and $q$ CTS12 on chromosome 12 at $9.2 \mathrm{Mb}-22.0$ Mb. The significant QTLs i.e. $q$ CTS1.1, qCTS3 and qCTS12 of this study contributed 50.7, 39 and $52.7 \%$ to the total phenotypic variation, respectively. QTLs with such higher phenotypic contribution were also reported by many other researchers. For example, $q$ LT3-1 (35\% PV) on chromosome 3 was reported by Fujino et al. (2004), similarly qSCT3-1 (24.5\% PV) on chromosome 3 and $q C T S 12 a(40.6 \% \mathrm{PV})$ on chromosome 12 were reported by Andaya and Mackill (2003). The identified QTLs, $q$ CTS1.1, qCTS3 and $q$ CTS12 were found tightly linked with RM490, RM218 and RM1261, respectively. The $q C T S 1.1$ and $q C T S 3$ showed negative additive effects while $q$ CTS12 showed positive value, which indicated that the favorable alleles of the former two QTLs for cold tolerance were inherited from donor parent BR18 and that of latter was arisen from susceptible parent BR1.

\section{Acknowledgements}

The authors acknowledge BRRI for granting funds and giving laboratory support for this study. They are also grateful to the Head of Plant Breeding Division, BRRI for sharing mapping population and parental materials.

\section{References}

Andaya VC and Mackill DJ 2003. Mapping of QTLs associated with cold tolerance during the vegetative stage in rice. J. Exp. Bot. 54: 2579-2585.

Bing Z, Qi-Ming D, Qi-Jun Z, Jie-Qin L, Shao-Ping Y, Yong-Shu L, Yong P and Ping L 2006. Analysis of segregation distortion of molecular markers in $\mathrm{F}_{2}$ population of rice. Acta Gene. Sinica. 33: 449-457.

Biswas PS, Khatun H, Anisuzzaman M and Hwang HG 2012. Study on the cold tolerant rice varieties for Bangladesh, In: Development of Research Capacity of the Bangladesh Rice Research Institute. Korea International Cooperation Agency: The Republic of Korea, p. 86.

Collard BZ, Jahufer MZZ, Brouwer JB and Pang ECK 2005. An introduction to markers, quantitative trait loci (QTL) mapping and marker-assisted selection for crop improvement: the basic concepts. Euphytica 142: $169-196$.

Fujino K, Sekiguchi H, Sato T, Kiuchi H, Nonoue Y, Takeuchi Y, Ando T, Lin SY and Yano M 2004. Mapping of quantitative trait loci controlling low-temperature germinability in rice (Oryza sativa L.). Theor. Appl. Genet. 108: 794-799.

Han L, Qiao Y, Zhang S, Zhang Y, Cao G, Kim J, Lee K and Koh H 2007. Identification of quantitative trait loci for cold response of seedling vigor traits in rice. J. Genet. Genomics 34: 239-246.

IRRI 2013. Stand Evaluation System of Rice. $5^{\text {th }}$ Edition, International Rice Research Institute, Philippines, $55 \mathrm{p}$.

Khatun H, Biswas PS, Hwang HG and Kim KM 2016. A quick and simple in-house screening protocol for cold tolerance at seedling stage in rice. Plant Breed. Biotech. 4: 373-378 
Kim SM, Suh JP, Lee CK, Lee JH, Kim YG and Jena KK 2014. QTL mapping and development of candidate gene-derived DNA markers associated with seedling cold tolerance in rice (Oryza sativa L.). Mol. Genet. Genomics 289: 333-343.

Lander ES and Botstein D 1989. Mapping Mendelian factors underlying quantitative traits using RFLP linkage maps. Genetics 121: 185-199.

Liu FX, Xu WY, Song Q, Tan LB, Liu JY, Zhu ZF, Fu YC, Su Z and Sun CQ 2013. Microarray-assisted fine-mapping of quantitative trait loci for cold tolerance in rice. Mol. Plant 6: 757-767.

Lou Q, Chen L, Sun Z, Xing Y, Li and, Xu X 2007. A major QTL associated with cold tolerance at seedling stage in rice (Oryza sativa L.). Euphytica 158: 87-94.

McCouch SR, Chen X, Panaud O, Temnykh S, Xu Y, Cho YG, Huang N, Ishii T and Blair M 1997. Microsatellite marker development, mapping and applications in rice genetics and breeding. Plant Mol. Biol. 35: 88-99.

Nelson JC 1997. QGENE: Software for marker-based genomic analysis and breeding. Mol. Breed. 3: 239245.

Park KI, Oh CS, Kim DM, Yeo SM and Ahn SN 2013. QTL mapping for cold tolerance at the seedling stage using introgression lines derived from an Inter sub-specific cross in rice plant. Breed. Biotech. 1: 1-8.

Ranawake AL, Manangkil OE, Yoshida S, Ishii T, Mori N and Nakamura C 2014. Mapping QTLs for cold tolerance at germination and the early seedling stage in rice (Oryza sativa L). Biotech. Biotechnol. Equipt. 28: 989-998.

Septiningsih EM, Sanchez DL, Singh N, Sendon PMD, Pamplona AM, Heuer S and Mackill DJ 2012. Identifying novel QTLs for submergence tolerance in rice cultivars IR72 and Madabaru. Theor. Appl. Genet. 124: 867-874.

Suh JP, Lee CK, Lee JH, Kim JJ, Kim SM, Cho YC, Park SH, Shin JC, Kim YG and Jena KK 2012. Identification of quantitative trait loci for seedling cold tolerance using RILs derived from a cross between japonica and tropical japonica rice cultivars. Euphytica 184: 101-108.

Syed MA, Iftekharuddaula MK, Mian MAK, Rasul MG, Rahmam GKMM, Panaullah GM, Lauren JG, Duxbury JM and Biswas PS 2016. Main effect QTLs associated with arsenic phyto-toxicity tolerance at seedling stage in rice (Oryza sativa $\mathrm{L}$ ). Euphytica 209: 805-814.

Verma SK., Xalxo, MS, Saxena RR and Verulkarl SB 2014. Identification of QTL for cold tolerance at seedling stage in rice (Oryza sativa L.). Indian J. Genet. 74: 86-89.

Yang Z, Huang D, Tang W, Zheng Y and Liang K 2013. Mapping of quantitative trait loci underlying cold tolerance in rice seedlings via high throughput sequencing of pooled extremes. PLoS ONE 8: 68-33.

Zhang S, Zheng J, Liu B, Peng S, Leung H, Zhao J, Wang X, Yang T and Huang Z 2014. Identification of QTLs for cold tolerance at seedling stage in rice (Oryza sativa $\mathrm{L}$ ) using two distinct methods of cold treatment. Euphytica 195: 95-104.

Zhang Q, Jiang N, Wang GL, Hong Y and Wang Z 2013. Advances in understanding cold sensing and the cold-responsive network in rice. Adv. Crop Sci. Tech. 1: 104.

Zhang ZH, Su L, Li W, Chen W and Zhu YG 2005. A major QTL conferring cold tolerance at the early seedling stage using recombinant inbred lines of rice (Oryza sativa L). Plant Sci. 168: 527-534.

Zhi-Juan JI, Zeng YX, Zeng DI, Ma LY, Li XM, Liu BX and Yang CD 2010. Identification of QTLs for rice cold tolerance at plumule and 3-leaf-seedling stages. QTL Net. 23: 11-12. 